\section{Climate Change Adaptation in Cameroon's Model Forests}

Changes in climate and extreme weather events disrupt agrifood production systems. This can cause significant food security and livelihood challenges in countries such as Cameroon where many smallholders are farming and collecting forest products for subsistence.

"People can no longer count on regular rainfall," says Gabriel Sarasin, B-ADAPT project manager. "They need support to make their farming more resistant to drought. And they need to make some money to have in their pocket-food is important, but they need to have some savings, especially if they have health problems or a bad farm year."

The implementation of effective climate-smart agricultural and agroforestry practices can improve productivity and the well-being of local people, while building on the traditional smallholder-based landscape diversity and reducing deforestation. Through B-ADAPT (Eco-Agricultural Business for Adaptation to Changes in Climate), volunteers work with communities to increase agricultural productivity and build small businesses to increase resilience to challenges posed by changes in climate. Beneficiaries include women, youth and indigenous communities, all of whom are key to Cameroon's food system. The project aims to:

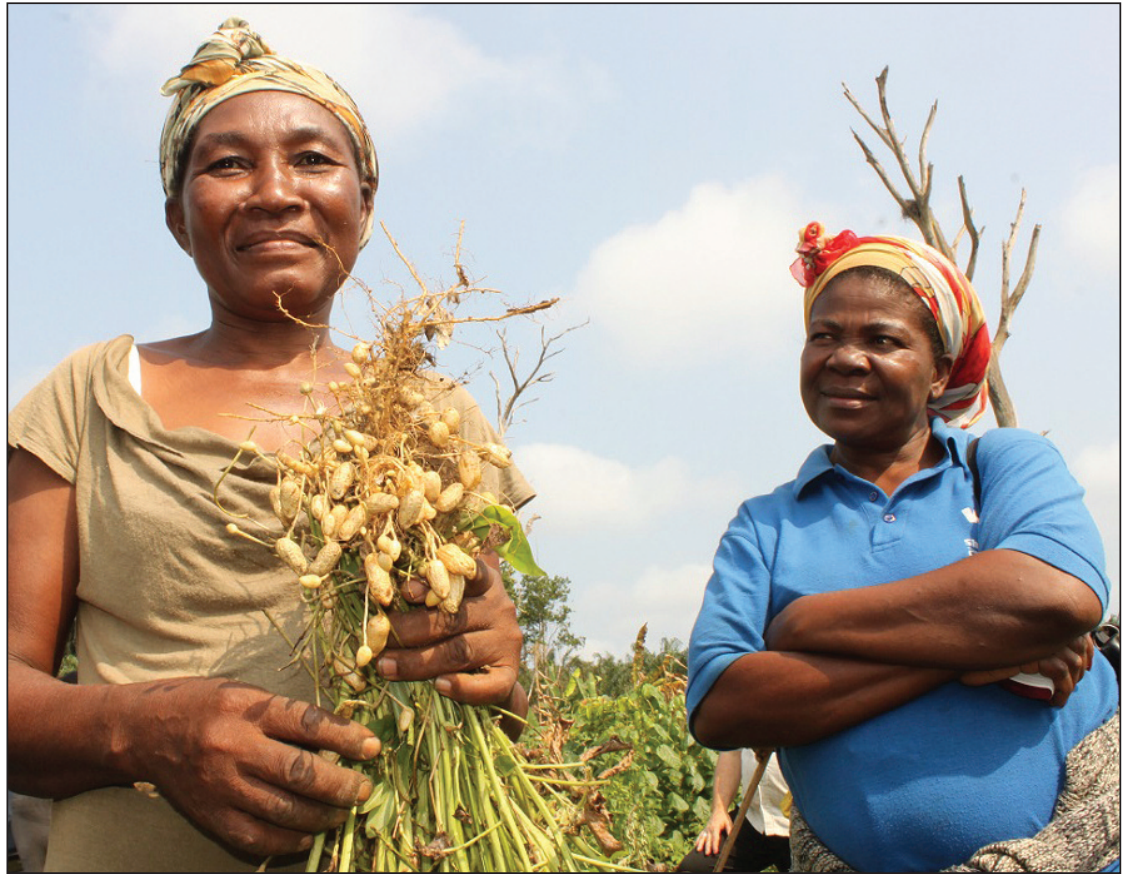

Two Cameroon farmers who are benefiting from participating in the model forest.

- Improve agricultural techniques including the use of bio-fertilizers;

- Promote the use of drought-resistant seeds;

- Strengthen marketing and explore new business opportunities based on a value chain approach.

The project is supporting 234 farmschools with 1948 producers in 226 villages in Cameroon's two Model Forests-Campo Ma'an and Dja et Mpomo. Sixty percent of the farm-

\section{African Model Forest Network}

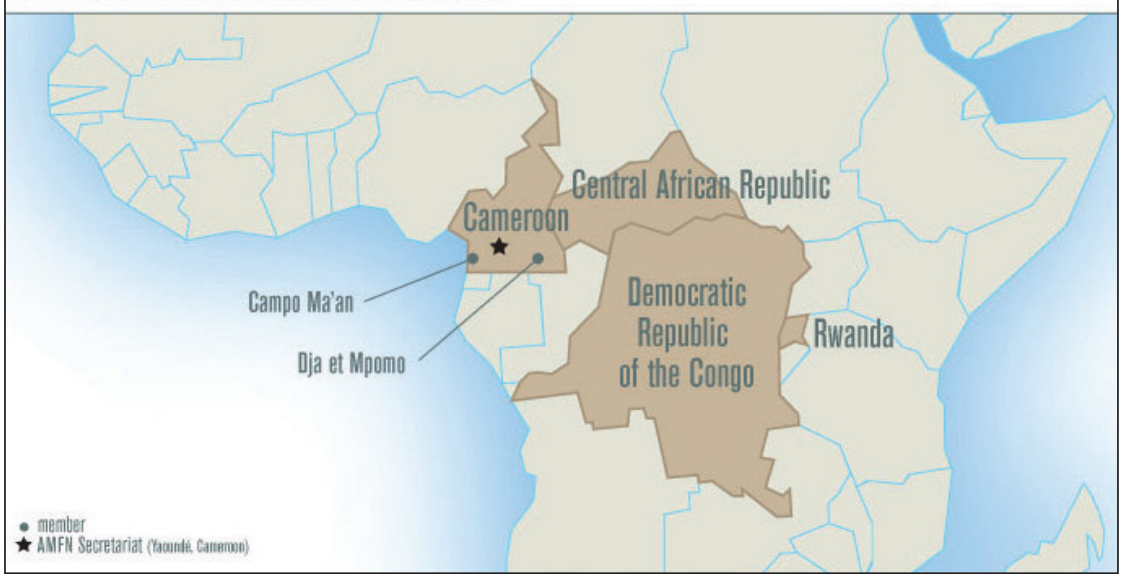

schools are led by women and indigenous people who serve as peer educators in their communities. The schools represent learning spaces where local farmers test and spread innovations to other farmers, and work together to access microfinance, reinforce value chains and gain better access to markets.

The governance structure of the Model Forests, reaching hundreds of communities, and the legacies of previous economic development capacity building projects allowed for the project's quick implementation and vast mobilization of farmers.

B-ADAPT is being implemented by CUSO International, the African Model Forest Network, and VSO Cameroon. It is funded through a grant from Canada's Department of Foreign Affairs, Trade and Development.

Source: IMFN-RIFM-RIBM

Press Release, 22/01/14 